\title{
Innovative approaches for strengthening existing concrete structures
}

\author{
Norbert Randl ${ }^{1, *}$ \\ ${ }^{1}$ Carinthia University of Applied Sciences (CUAS), 9800 Spittal, Austria
}

\begin{abstract}
The demand of effective and low-invasive methods for strengthening existing concrete structures is continuously increasing due to the ageing infrastructure. High performance materials can beneficially be applied to provide sustainable and robust strengthening solutions. The present article presents some exemplarily selected methods and innovative approaches for subsequent strengthening of existing RC structures. Main results of experimental investigations are summarized and future research topics identified.
\end{abstract}

\section{General aspects of strengthening reinforced concrete structures}

In industrial countries, the ever-increasing percentage of existing buildings and structures requires significant efforts in maintenance, retrofitting and rehabilitation of this heritage. The high traffic loads create an increasing demand of low-invasive techniques for structural strengthening that do not lead to significant traffic disturbances and interruptions. Moreover the global challenge of reducing $\mathrm{CO}_{2}-$ emissions and minimizing the ecological impact of construction activities has to be met in this context, too.

Strengthening techniques can be subdivided into local and global interventions with respect to the overall structural impact and the affected parts of the member. RC structures are typically strengthened either by increasing the compression zone and thereby the inner lever arm, or by adding various types of reinforcing materials. Frequently used global techniques are external pre-stressing of the whole structure or the application of bonded concrete overlays. Local strengthening can typically be done by adding bonded or nonbonded reinforcing bars. Some methods require changes of a member's cross section, while others do not really affect the circumference of the cross section. There are different methods to activate the subsequently applied strengthening system already under the structure's self-weight, typically pre-stressing or in general introducing deformations via external jacking forces are common approaches.

An observed trend is the increasing use of advanced high-strength materials, for example Ultra High Performance Concrete (UHPC) e.g. as subsequently applied bridge

\footnotetext{
* Corresponding author: n.randl@cuas.at
} 
deck overlay [1] or textile reinforced mortars as durable high-strength top layers in tensile zones [2]. UHPC may also serve for built-in strengthening solutions in a way that units of precast UHPC-elements are cast-in to overtake compression loads in highly stressed regions [3]. Some new developments in quite typical and subsequently applied strengthening techniques have been investigated in various research projects at CUAS and are exemplarily addressed in the following sections, providing an overview of some of the technical challenges and several research topics as well.

\section{High performance concrete overlays}

Subsequently applied concrete layers are a common method in repair and strengthening of existing RC structures. High Strength Concretes (HSC) as overlay material may provide several advantages such as increased robustness, extended durability and an increase of the overall structural stiffness. In addition there is evidence that the concrete-concrete bond strength increases with increasing overlay strength [4-6]. Other parameters involved are the viscosity and the mix proportions of the overlay concrete.

\subsection{Small scale bond tests}

The investigation of the effect of using HSC as overlay material on the adhesive bond has been in the focus of a recently conducted experimental campaign at CUAS [6, 7]. Various series of different small scale interface tension and shear tests have been performed to investigate the adhesive bond resistance between Normal Strength Concrete (NSC) and subsequently applied HSC with respect to different interface roughness categories. The surfaces of the substrates were roughened with high pressure water jetting (HPW) before placing the new concrete layer. Fig. 1 displays the produced 3 roughness categories.
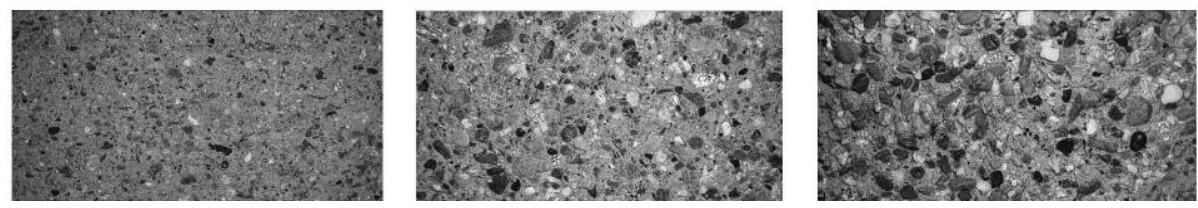

Fig. 1. Interface roughness: smooth - rough - very rough [6].

Push-out and slant shear test setups were chosen to derive the adhesive bond strength in shear along the interface between old (NSC) and new concrete (HSC) (setups see Fig. 2 (left hand side, with push-out setup to the very left)). Two HSC mixes were investigated, "HSC1" with a compressive strength around $88 \mathrm{MPa}$ and "HSC2" with a compressive strength around $102 \mathrm{MPa}$ (the latter one with a higher workability).
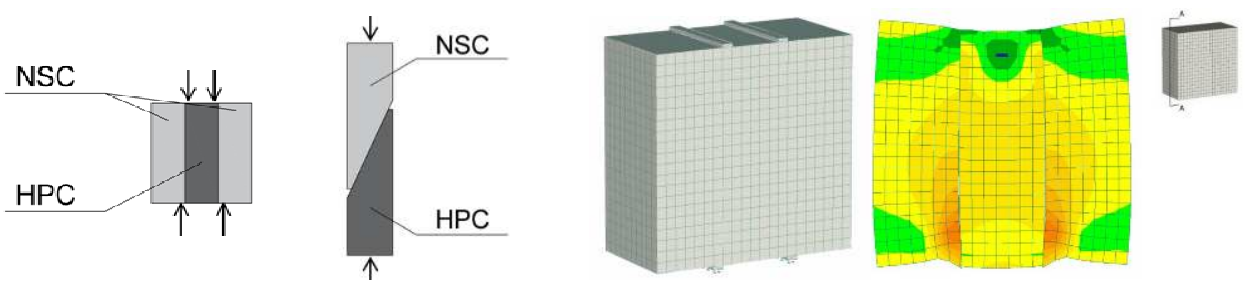

Fig. 2. Interface shear test-setups (left) and FE-model of push-out test (right) [6].

In addition pull-off tests were performed on drilled cores to identify the possible linkage to the tensile bond strength. While push-out tests deliver more or less the pure interface shear strength (apart from some normal stresses due to unavoidable load eccentricities, see 
Fig. 2 (right hand side)), the slant shear setup leads to a superposition of normal and shear forces along the interface. However, in general it has to be mentioned that in concrete with its non - homogeneous structure, discontinuities are unavoidable so that local concentrations of stresses may always occur (see discussion of basic types of micro cracks and complex state of stress when concrete is subject to shear (fracture mode II) in [8] and results of according numerical simulations in [9]). While in the push-out tests considered in here due to the pre-defined joint the failure cracks usually developed directly along the interface, the mentioned local stress concentrations are surely one of the reasons for quite a large scatter in such small-scale shear test results.

It turned out clearly that with an appropriate HPC mixture significantly higher shear bond strength can be achieved than usually with NSC overlays (Fig. 3). Concerning the effect of roughness, shifting from smooth to rough interface (up to $1.5-2.0 \mathrm{~mm}$ mean roughness depth) leads to a pronounced bond strength increase especially in the more sensitive push-out tests, while no significant difference occurs from rough to very rough. Strong surface wetting before casting the overlay has a rather unfavourable effect on the adhesive bond in comparison to an only slightly wetted surface representing SSDconditions. Fig. 3 also shows that better workability (denominated as "HSC2") leads to significantly higher bond properties than a stiffer mix ("HSC1").
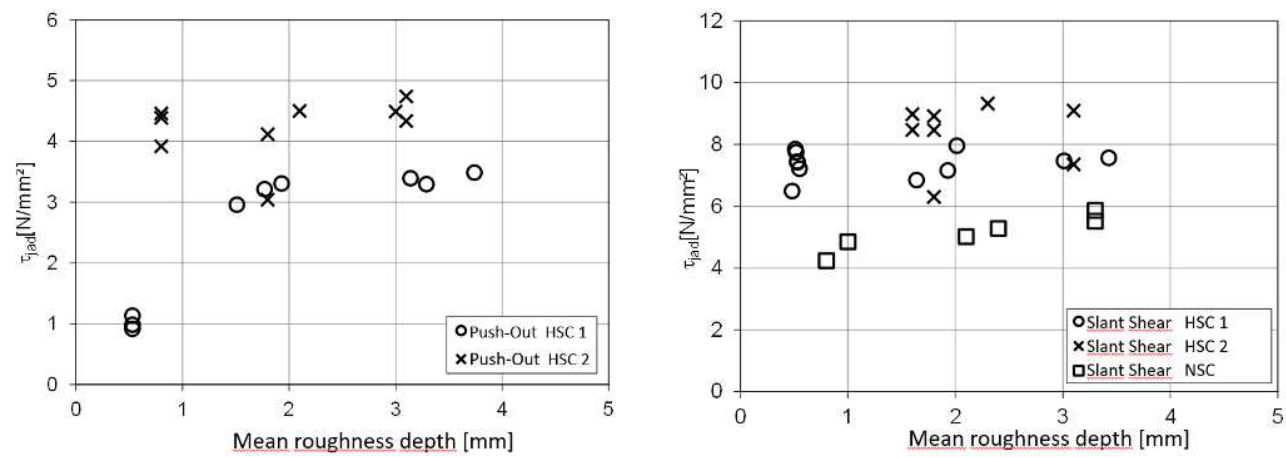

Fig. 3. Results from push-out (left) and slant shear setups (right) [7].

A numerical simulation of the small-scale tests has been performed with the ATENA software. Based on the finite element analysis, the differences in adhesive bond strength derived from push-out and slant shear setups can be explained. In slant shear tests the shear force is superimposed by a normal force perpendicular to the interface. Therefore the identification of the pure adhesive bond strength $\tau_{\mathrm{j}, \mathrm{ad}}$ requires the definition of a failure criterion. A simple but still sufficiently accurate and widely used approach to describe the shear resistance along an interface provided by bond and frictional forces is the MohrCoulomb hypothesis, a criterion that is also part of the basis for the current MC2010 design approach (Extended Shear Friction theory, see [10]). More advanced Mohr-Coulomb envelopes lead to a slightly more accurate judgement of the inherent adhesive bond strength [11]. Nevertheless, even if such criteria are applied to eliminate the theoretical effect of frictional forces, slant shear tests will still provide higher bond values than push-out tests (see comparison in Fig. 3) and thus lead to rather beneficial strength data [11, 12].

\subsection{Member tests with HSC overlays}

The above described small scale tests were followed up by member tests (see more details in [13]): a number of 10 slabs, each of them $3.6 \mathrm{~m}$ long and subsequently provided with $60 \mathrm{~mm}$ thick either NSC or HSC overlays, were subjected to four point flexural and shear 
loading. All slabs failed finally in shear as designed for, with the decisive shear crack protruding from the support to the load introduction zone (Fig. 4). Just looking at the achieved failure loads did first of all not provide a clear picture of an effect of the overlay material, as the HSC resulted just in a slight average increase of the ultimate load. However, a deeper look at the interface degradation revealed an important aspect: while the slabs strengthened with an HSC overlay showed hardly any sign of crack offsets, i.e. cracks following the interface (see e.g. front view of crack pattern at slab 2 displayed in Fig. 4), slabs provided with NSC overlays displayed clear indications of local degradation along the interface between old and new concrete [13]. The relevant shear stresses were backcalculated from strain measurements along the concrete overlay and the longitudinal reinforcement. Thereby evidence was provided, that back-calculated shear stresses along interfaces showing some degradation corresponded quite well to the shear bond strength derived from push-out tests with the same interface roughness [13]. This observation also confirms that push-out tests, provided eccentricities between load introduction and support are kept as small as possible, deliver reliable and more accurate shear bond results than various other types of related small scale tests.

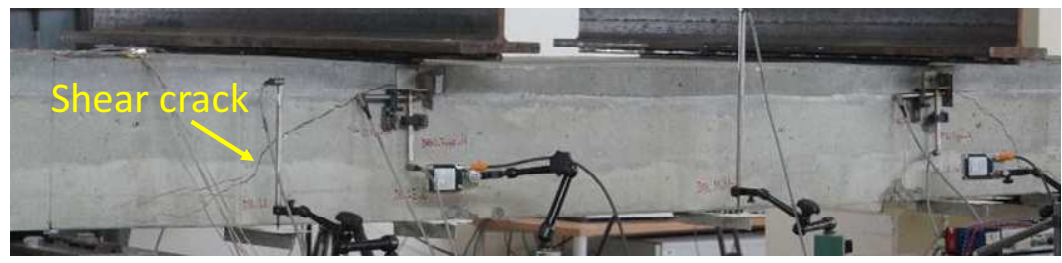

Fig. 4. Shear failure of RC member strengthened with HSC overlay at CUAS lab.

\subsection{Verification of bond strength on site}

In case that verification of the bond strength on site is required, it is common practice in many countries to perform pull-off tests. The procedure is as follows: First of all a core is drilled perpendicularly trough the overlay and about 10 to $20 \mathrm{~mm}$ into the substrate concrete. Then the adapter of the pull-off device is glued to the top surface of the core and the force is applied. Unfortunately, in many situations rupture will not occur at the interface, but more often in the substrate or, depending on the concrete strength, sometimes even in the overlay. However, such load values may be considered at least as lower bound values of the real interface bond strength in tension.

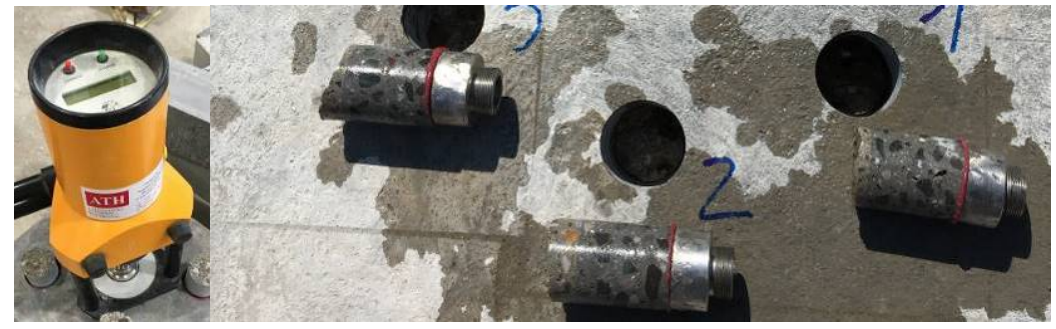

Fig. 5. Pull-off device and cores drilled through HSC overlay after pull-off test.

The more fundamental question is how to judge the tensile bond strength with respect to the usually required shear bond strength. The reported range of results displaying the ratio of shear bond vs. tensile bond strength varies strongly from 0.8 up to 2.0 [14] or even 2.4 [15], which shows that there is a variety of influencing parameters to be taken into account. First of all, pull-off test results depend strongly on a thorough execution during drilling as well as installation and positioning of the pulling-device. On the other hand interface shear 
tests are not regulated and the variation of different setups is large, each of them providing different results. Above all, the surface texture affects tensile bond strength and shear bond strength in a different way - a rougher interface promotes the shear bond strength more than the tensile bond strength. A recent study [11] compared various interface shear test setups and came to the conclusion that in the considered tests with a mean roughness depth close to $1.5 \mathrm{~mm}$, the shear bond strength was just about $60 \%$ of the related tensile bond strength.

The use of high strength overlay concrete will lead to potentially higher bond strength between overlay and substrate. In order to make use of higher bond strength values, tensile bond tests on site are highly recommended for verification. In the above mentioned member tests, series of pull-off tests were performed after the structural tests [13], all of them in zones without visible degradation in the overlay or interface zone respectively. While with HSC overlays usually rupture in the substrate concrete was observed (Fig. 5), several cores drilled into the NSC overlay broke at the level of the interface [13]. Therefore this was another confirmation of the extraordinary bond strength reached with the high strength concrete. The investigations however also showed that the workability and the fresh concrete properties may affect the bond strength significantly [7], larger slump flow of the overlay concrete will usually lead to stronger adhesive bond than a rather stiff mix. In the mentioned study, the recorded tensile bond strength was close to the shear bond strength gained from push-out tests.

\subsection{Application of textile reinforced concrete layers}

Textile reinforced concrete is a rather new high performance material that can be used to advantage for subsequent strengthening of RC structures with concrete overlays on the tensile side [2]. The main benefits in that context result from the high tensile strength of the used fibres (especially valid for carbon material), its high resistance against corrosion and some deformability of the rovings (especially if non epoxy-coated), allowing for adaption to the shape of the existing concrete surface.

Textile reinforcement with its narrow meshing requires the combination with appropriate mortars or rather fine grain concrete mixes. In a recent study at CUAS, the combination of textile-reinforcement and Ultra High Performance Concrete (UHPC) in strengthening beams with a textile reinforced concrete layer was investigated. Even though UHPC is not necessarily required in that context with respect to the predominating tensile loading, the fine grain composition and the high bond strength generated between UHPC and NSC, but also between UHPC and textile reinforcement, provide some arguments for such material combination.

For this purpose, 18 identically reinforced standard concrete girders $(2500 \mathrm{x} 250 \mathrm{x}$ $140 \mathrm{~mm}$ ) were produced and tested in a 3 point setup (details of this study are provided in [16]), two of them serving as reference beams without strengthening. In order to study the effectiveness of different textiles, two types of textile (Carbon and AR-glass; both impregnated with epoxy resin) with different mesh geometry were used $(21,25$ and 38 $\mathrm{mm})$. The NSC beams were deliberately roughened at the bottom side via sandblasting (mean roughness depth: $1.1 \mathrm{~mm}$ ). The thickness of the subsequently applied UHPC layer was $30 \mathrm{~mm}$, so that the effective depth from top surface to textile layer amounted $160 \mathrm{~mm}$. In parallel accompanying push-out and slant shear tests were performed to determine the adhesive bond strength. The 28-day compressive strength of the UHPC on $100 \mathrm{~mm}$ cubes was $168.7 \mathrm{MPa}$. 
The bending tests resulted in flexural failure with rupture of the textile layer and some delamination in the case of the carbon textile (Fig. 6). A clear load increase compared to the non-reinforced reference beams was observed: the load gain was up to $73 \%$ with carbon textile reinforcement and a cross-sectional area of just $142 \mathrm{~mm} / \mathrm{m}$ (grid size $38 \mathrm{~mm}$ ) whereas with AR-glass and almost the same cross-section $\left(145 \mathrm{~mm}^{2} / \mathrm{m}\right.$, grid size $\left.25 \mathrm{~mm}\right)$ a maximum load increase of up to $34 \%$ was recorded. Pull-off tests performed afterwards directly on the beams in non-damaged zones yielded a tensile bond strength of $2.54 \mathrm{MPa}$ between textile reinforced UHPC and NSC and ended up predominantly with rupture along the interface or at the textile layer, while push-out tests resulted in an average interface shear strength between NSC and subsequently applied UHPC of 3.9 MPa. In that case, a rather high ratio of 1.54 between push-out and pull-off results was observed, but the tensile pull-off strength was partly limited by premature rupture at the level of the textile layer. The high adhesive bond strength values achieved with UHPC were similar to the push-out results observed with an adequate HSC (see Fig. 3 left hand side, compare to strength data with mix "HSC2"). Overall, the particular suitability of such combination of high performance material ((U)HPC and carbon textile reinforcement) for strengthening RC structures with subsequently applied concrete layers was clearly confirmed.

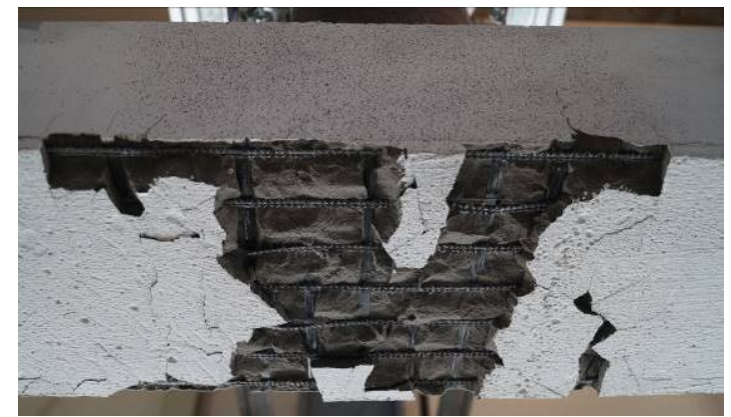

Fig. 6. Bending failure of beam strengthened with TRC-layer at the bottom side (CUAS lab).

\section{Local strengthening in shear}

There are just a few recognized methods for local strengthening of shear deficient RC members (see typical examples in [17]). Basic techniques are the application of externally bonded reinforcement, near surface mounted reinforcement or externally anchored or grouted steel bars inserted into pre-drilled holes. As material for externally bonded or near surface mounted reinforcement, (carbon) fiber reinforced plastics ((C)FRP) are increasingly used due to the strength to weight ratio, durability, and ease of application.

\subsection{Addition of reinforcing bars}

An already frequently applied method involves bonded reinforcing bars, installed in the existing concrete substrate by drilling holes, injecting them and placing the bars. The efficiency of this method has been verified in a series of beam tests [18], showing the potential increase in shear resistance. A $45^{\circ}$ - inclination of the bars is recommended to provide sufficient end anchorage length. Even though the inclination requires some additional efforts in the installation process, it leads to a better utilization of the bars as the shear cracks are crossed nearly perpendicularly. Above that, it was observed thereby that the dowel action effect [19] can be mobilized in the inclined rebars . 
Recently, a new type of undercut anchor was designed for subsequent strengthening of $\mathrm{RC}$ members in shear [20]. The anchor is set vertically into pre-drilled holes and introduces the load at the very end by means of a self-undercutting expansion sleeve. A special feature is the option to introduce a certain pre-stressing force via the applied torque. In a series of member tests (Fig. 7) a significant increase of the beam's shear resistance ( +40 to $+90 \%)$ was observed, even with a low number of only 4 to 7 installed anchors $\varnothing 12 \mathrm{~mm}$. The strengthened side of the beam was designed without internal shear reinforcement in order to study the full potential contribution of the strengthening elements. The failure sequence and the crack pattern (Fig. 8) showed that, similar to cast-in stirrups, a truss model developed and the use of a number of anchors at a distance below the height of the inner lever arm led to some redundancy so that failure of one rod did not result in a total collapse of the beam. An appropriate design of the end anchorage is however a decisive factor to allow for full utilization of the tensile strength of the rods.
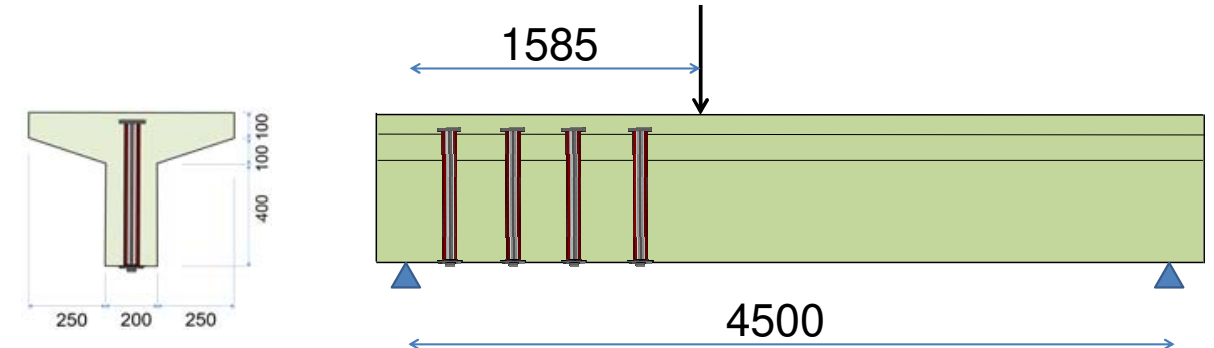

Fig. 7. Setup of beam tests strengthened with post-installed undercut anchors (units: [mm])
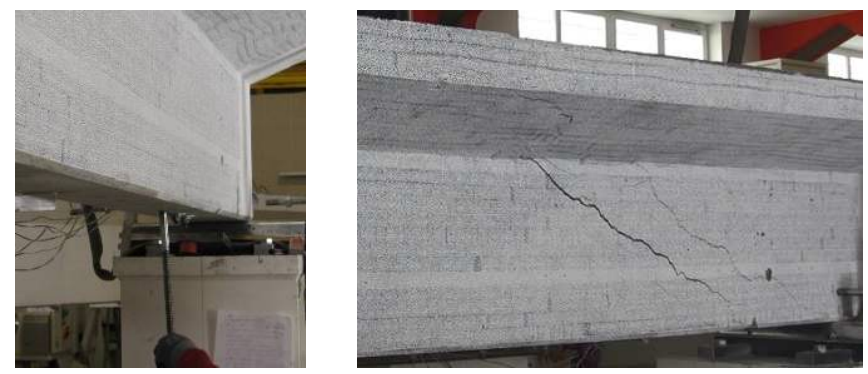

Fig. 8. Installation of anchors and observed main failure cracks

\subsection{Properly anchored CFRP sheets}

Numerous researchers have already proven the efficiency and usefulness of applying CFRP sheets to strengthen existing RC structures in shear (see e.g. [21 - 24]). If not fully wrapped around, without adequate end anchorage the governing failure mode will be lateral delamination, i.e. de-bonding, of the CFRP ends from the concrete.

Following the before mentioned campaign with undercut anchors, another series of beams with same geometry (Fig. 7) and reinforcement layout was strengthened with CFRP sheets (details are provided in [20]). In order to avoid premature de-bonding, a simple endanchorage system has been designed which allows a direct load transfer into the compression zone. The varied parameters in the tests with CFRP sheets were the number of glued CFRP-layers in one sheet (either one or two layers, one glued upon the other) and the number resp. distance of these sheets. The elastic modulus of the used CFRP sheets was close to $100 \mathrm{GPa}$. 
The developed end anchorages (see Fig. 9) consisted of rounded steel plates which were attached via two rapidly curing high-bond anchors each to the upper flange of the T-beam, thus enabling direct load transfer to the compression zone (for more details see [20]). The anchorage prevented successfully any de-bonding of the CFRP and thus allowed for the formation of a full truss mechanism, utilizing the complete effective depth of the RC member. Concerning the actual failure modes, with two-layered CFRP sheets crushing of the concrete struts in compression was observed, while configurations with one-layered CFRP sheets led to rupture of the CFRP material.

In addition to traditional measurement techniques for shear tests (see for example an evaluation of standard devices in [25]), a photogrammetric measurement system together with digital image correlation software (DIC) was successfully used (Fig. 9, right hand side). For this purpose, two pairs of high resolution cameras were used to track the displacements of the surface points. The achieved resolution of the strain measurements with the used technique is very high, with values down to about $10 \mu \varepsilon$. Depending on the distance between camera and specimen and the camera-recording angle, displacements with an accuracy around or even below $0.01 \mathrm{~mm}$ are well captured.

The DIC evaluation clearly showed that, due to the effective end anchorage, in each test one of the sheets reached a maximum strain quite close to the mean axial fracture strain of about $11.0 \mathrm{~mm} / \mathrm{m}$ according to manufacturer's tensile tests. The DIC pictures show, however, that actually in each test not more than one strip was activated to that extent, which is attributed to the more or less linear-elastic behaviour up to tensile failure and lack of a redistribution of forces at higher load levels with that type of high-strength material.
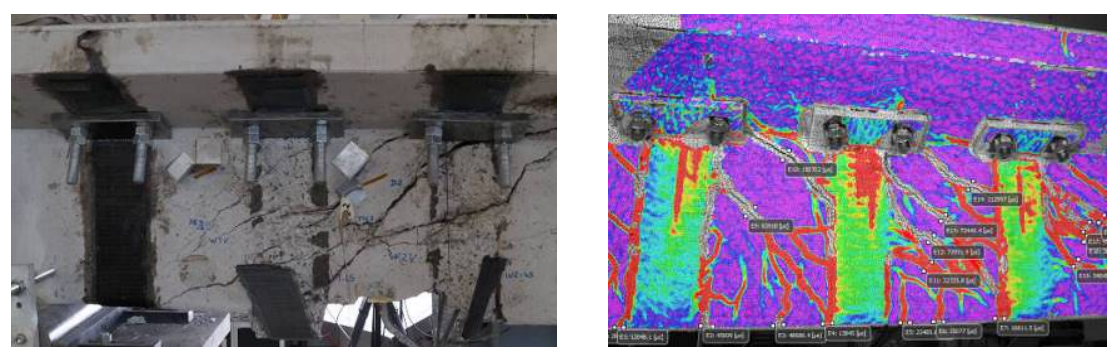

Fig. 9. Typical shear failure of CFRP strengthened beam and strain / crack pattern from DIC.

Comparing the herein presented two strengthening methods in shear, with the CFRP an even higher shear load gain $(+100 \%$ to $+160 \%)$ was achieved than with the before described anchors. However, due to the missing redistribution option with CFRP the load increase is less pronounced with increasing number of single strengthening elements than in the case of steel rebars or anchors.

In both cases a full truss mechanism developed and failure was due to either rupture of a strengthening element or (in the case of the 2-layered CFRP strengthening) failure of a concrete compression strut. Therefore design can be handled similarly to the standard design procedure for a shear reinforced member, treating the strengthening elements analogously to cast-in shear reinforcement (as also proposed in [24]). Depending on the effectiveness of the anchorage, for such an approach a reduction factor taking into account the material utilization has to be introduced. In the present tests, it was seen that the postinstalled undercut anchors were fully utilized whereas for the used CFRP strips, depending on the number of layers, a specific reduction factor in the range of 0.7 to 0.8 was to be considered [20] when applying codes of practice such as Eurocode 2 or Model Code 2010. 


\section{Outlook on future research topics}

Strengthening of existing structures is nowadays becoming more and more an every-day task in civil engineering. Promising high strength material combinations play thereby an increasingly important role and provide advantages in terms of material consumption, lowinvasive application techniques, achievable load gain and stiffness behaviour of the strengthened structure. Attention has to be further laid on ease of installation and, under load, on robustness and potential redundancy provided by the strengthening elements.

The further optimization and the design of such strengthening solutions is still facing several tricky tasks that are subject to current and future research activities such as:

- Appropriate load transfer between existing structure and subsequently applied strengthening system

- Activation of strengthening system at an early stage, preferably already at SLS-level

- Evaluation of the effect of different material stiffness on compatibility and overall load bearing behaviour

- Interaction between existing reinforcement and subsequently applied strengthening elements

- Effect of existing degradation of the old structure on the effectiveness of the strengthening system

- Effect of traffic loads (acting in parallel during application of the strengthening system) on bond topics and later effectiveness of the elements

- Harmonization of test setups evaluating concrete-to-concrete bond

- Realistic computational modelling of such type of composite RC structures, including construction stages and considering short-term as well as long-term loading

Parts of the herein presented experimental campaigns have been funded by the Austrian Research Promotion Agency FFG (grant no. 866881) and by FFG, ASFINAG and ÖBB Infrastruktur (grant no. 840549) which is gratefully acknowledged. A part of the presented tests with HSC overlays has been funded by the following members of the ÖBV: ASFiNAG, ÖBB-Infrastruktur, PORR, STRABAG und RTB ROHRDORFER Transportbeton. The author also like to thank the industrial partners Hilti and SIKA Austria for the fruitful cooperation in the project "Querkraftverstärkung". Special thanks is directed to the involved team of the CUAS lab, especially Peter Harsanyi, Bernhard Hofer, Tamas Meszöly, Sandra Ofner, Martin Steiner and Thomas Steiner.

\section{References}

1. E. Brühwiler, Strengthening of existing structures using R-UHPFRC: Principles and conceptual design. UHPFRC 2017, Montpellier, France, 993-1002 (2017).

2. L.N. Koutas, Z. Tetta, D.A Bournas., T.C. Triantafillou, Strengthening of Concrete Structures with Textile Reinforced Mortars: State-of-the-Art Review, J. Compos. Constr., 23, 1, (2019).

3. M. Ricker, F. Häusler, N. Randl, Punching strength of flat plates reinforced with UHPC and doubleheaded studs, Eng. Struct., 136, 345-354 (2017).

4. E. Júlio, F. Branco; V. Silva, J. Lourenco, Influence of added concrete compressive strength on adhesion to an existing concrete substrate, Build. Env., 41, 1934-1939 (2006).

5. M. Munoz, D. Harris, T. Ahlborn, D. Froster, Bond Performance between UltrahighPerformance Concrete and Normal-Strength Concrete, J. Mater. Civ. Eng. (2013). 
6. N. Randl, M. Peyerl, M. Steiner, Sustainable strengthening of RC members with High Performance Concrete overlays, IABMAS 2016, Proceedings, 1308-1315 (2016).

7. N. Randl, M. Peyerl, M. Steiner, Hochfester Aufbeton zur Tragwerksverstärkung, Teil 1: Kleinkörperversuche, Beton- und Stahlbetonbau, 115, 2, 106-116 (2020).

8. G. Golewski, T. Sadowski, Fracture Toughness at Shear (Mode II) of Concretes Made of Natural and Broken Aggregates, Brittle Matrix Compos. 8, 537-546 (2006).

9. G. Golewski, T. Sadowski, Experimental Investigation and Numerical Modeling Fracture Processes under Mode II in Concrete Composites Containing Fly-Ash Additive at early Age, Sol. State Phenom., 188, 158-163 (2012).

10. N. Randl, Design recommendations for interface shear transfer in fib Model Code 2010, Struct. Concr., 14, 3, 230-241 (2013).

11. C. Zanotti, N. Randl, Are concrete-concrete bond tests comparable?, Cem. Concr. Compos., 99, 80-88 (2019).

12. Đ. Čairovic, A. de la Fuente $A, M$. Zlámal, et al, Suitability of different tests for characterization of the dimpled concrete-to-concrete interface. Struct. Concr., 1-18 (2020).

13. N. Randl, M. Steiner, M.: Hochfester Aufbeton zur Tragwerksverstärkung, Teil 2: Bauteilversuche, Beton- und Stahlbetonbau, 115, 5, 375-384 (2020) (in German).

14. B. Bissonnette, L. Courard, D.W. Fowler, J.-L. Granju (Eds.), Bonded Cement-Based Material Overlays for the Repair, the Lining or the Strengthening of Slabs or Pavements, State-of-the-Art Report of RILEM Technical Committee 193-RLS (2011).

15. J. Silfwerbrand, Shear bond strength in repaired concrete structures, Mater. Struct., 36, 419-424 (2003).

16. T. Mészöly, S. Ofner, N. Randl, Mechanical properties of glass and carbon textile reinforced UHPC, Proceedings of the fib Symposium 2019: Concrete Innovations in Materials, Design and Structures, 289-296 (2019).

17. B. B. Adhikary, H. Mutsuyoshi, Shear strengthening of reinforced concrete beams using various techniques. Constr. Build. Mater., 20, 6, 366-373 (2006).

18. N. Randl, J. Kunz, Biegeschubversuche an Stahlbetonbalken mit nachträglich eingemörtelter Querkraftbewehrung, Beton- und Stahlbeton, 104, 11, 728-736 (2009).

19. N. Randl, Load Bearing Behaviour of Cast-in Shear Dowels, Beton- und Stahlbetonbau, 102, 1, 31-37 (2007).

20. N. Randl, P. Harsányi, Developing optimized strengthening systems for shear-deficient concrete members, Structural Concrete, 19, 1, 116-128 (2018).

21. T.C. Triantafillou, Shear Strengthening of Reinforced Concrete Beams Using Epoxy-Bonded FRP Composites. ACI Struct. J., 95, 2, 107-115 (1998).

22. A. Belarbi, S.-W. Bae, A. Brancaccio, Behavior of full-scale RC T-beams strengthened in shear with externally bonded FRP sheets. Constr. Build. Mater., 32, $27-40$ (2012).

23. A. Khalifa, A. Nanni, Rehabilitation of rectangular simply supported RC beams with shear deficiencies using CFRP composites. Constr. Build. Mater., 16, 3, 135-146 (2002).

24. I. Bukhari, R. Vollum, S. Ahmad S, J. Sagaseta, Shear strengthening of reinforced concrete beams with CFRP, Mag. Concr. Res., 62, 1 65-77 ( 2010).

25. J. Stoerzel, N. Randl, A. Strauss, Monitoring shear-induced degradation of reinforced and pretensioned concrete members, IABSE Conference Report, Geneva 2015, 1148-1157 (2015). 